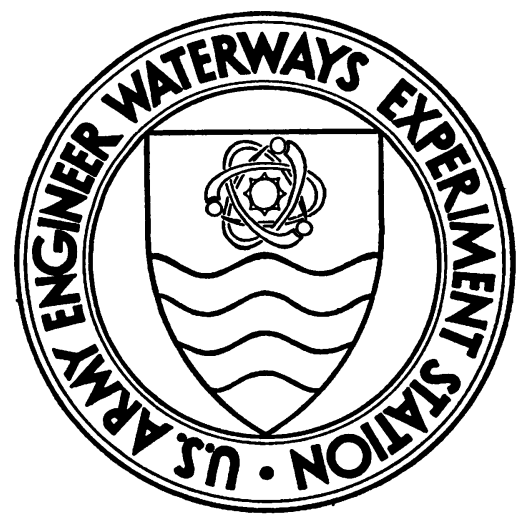

MISCELLANEOUS PAPER S-73-16

\title{
CONDITION SURVEY, ROBERT GRAY ARMY AIRFIELD, FORT HOOD, TEXAS \\ by
}

\author{
P. J. Vedros, R. D. Jackson
}

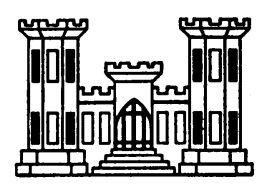

April 1973

Sponsored by Office, Chief of Engineers, U. S. Army

Conducted by U. S. Army Engineer Waterways Experiment Station

Soils and Pavements Laboratory

Vicksburg, Mississippi

ARMY-MRC VICKSBURG. MISS

APPROVED FOR PUBLIC RELEASE; DISTRIBUTION UNLIMITED 